\title{
Radical Anions from Urea-type Carbonyls: Radical Cyclizations and Cyclization Cascades
}

DOI:

10.1002/anie.201800667

\section{Document Version}

Accepted author manuscript

Link to publication record in Manchester Research Explorer

\section{Citation for published version (APA):}

Huang, H., McDouall, J. J. W., \& Procter, D. (2018). Radical Anions from Urea-type Carbonyls: Radical Cyclizations and Cyclization Cascades. Angewandte Chemie, 57(18), 4995-4999.

https://doi.org/10.1002/anie.201800667

\section{Published in:}

Angewandte Chemie

\section{Citing this paper}

Please note that where the full-text provided on Manchester Research Explorer is the Author Accepted Manuscript or Proof version this may differ from the final Published version. If citing, it is advised that you check and use the publisher's definitive version.

\section{General rights}

Copyright and moral rights for the publications made accessible in the Research Explorer are retained by the authors and/or other copyright owners and it is a condition of accessing publications that users recognise and abide by the legal requirements associated with these rights.

\section{Takedown policy}

If you believe that this document breaches copyright please refer to the University of Manchester's Takedown Procedures [http://man.ac.uk/04Y6Bo] or contact uml.scholarlycommunications@manchester.ac.uk providing relevant details, so we can investigate your claim.

\section{OPEN ACCESS}




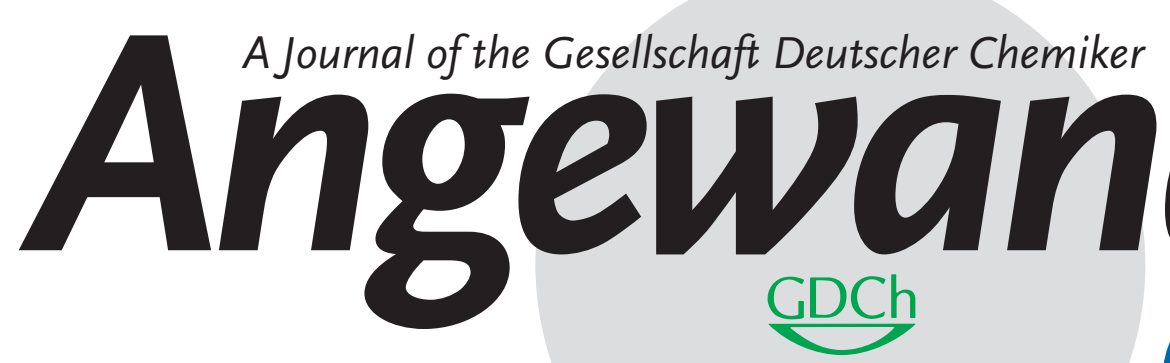

International Edition

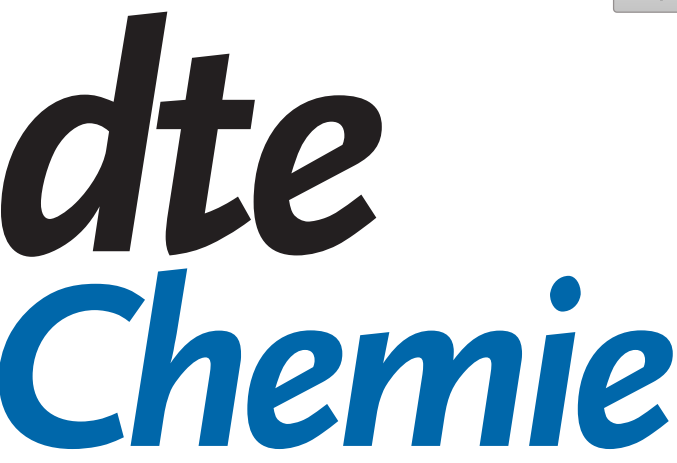

www.angewandte.org

\section{Accepted Article}

Title: Radical Anions from Urea-type Carbonyls: Radical Cyclizations and Cyclization Cascades

Authors: Huan-Ming Huang, Joseph McDouall, and David John Procter

This manuscript has been accepted after peer review and appears as an Accepted Article online prior to editing, proofing, and formal publication of the final Version of Record (VoR). This work is currently citable by using the Digital Object Identifier (DOI) given below. The VoR will be published online in Early View as soon as possible and may be different to this Accepted Article as a result of editing. Readers should obtain the VoR from the journal website shown below when it is published to ensure accuracy of information. The authors are responsible for the content of this Accepted Article.

To be cited as: Angew. Chem. Int. Ed. 10.1002/anie.201800667

Angew. Chem. 10.1002/ange.201800667

Link to VoR: http://dx.doi.org/10.1002/anie.201800667

http://dx.doi.org/10.1002/ange.201800667 


\title{
Radical Anions from Urea-type Carbonyls: Radical Cyclizations and Cyclization Cascades
}

\author{
Huan-Ming Huang ${ }^{[a]}$, Joseph J. W. McDouall ${ }^{[a]}$, and David J. Procter*[a]
}

\begin{abstract}
Radical anions generated from urea carbonyls by reductive electron transfer are exploited in carbon-carbon bond formation. New radical cyclizations of urea radical anions deliver complex nitrogen heterocycles and, depending upon the proton source used in the reactions, a chemoselective switch between reaction pathways can deliver two heterobicyclic scaffolds. A computational study has been used to investigate the selectivity of the urea radical processes. Furthermore, radical cyclization cascades involving urea radical anions deliver unusual spirocyclic aminal architectures.
\end{abstract}

Carbon-carbon bond formation is integral to almost any synthetic endeavor and provides a focal point for contemporary synthetic method development. ${ }^{[1]}$ Radical reactions constitute one of the most important and attractive tools to achieve carbon-carbon bond formation. ${ }^{[2]}$ In particular, radical cyclizations and cyclization cascades are prized for their ability to construct carbo and heterocyclic motifs, including those found in complex natural products, biologically-active molecules and materials. ${ }^{[3]}$

Within radical chemistry, ketyl radicals, typically derived by single electron transfer (SET) reduction of aldehydes and ketones, hold high status as one of the most important and versatile classes of open shell intermediates for use in synthesis. ${ }^{[4]}$ Cyclization reactions involving ketyl radicals inherently give oxygenated cyclic products, often possessing valuable three-dimensional shape, and have been achieved by deploying reagents based on $\left.\mathrm{Sm}(\mathrm{II}),{ }^{[5]} \mathrm{Ti}(\mathrm{III}),{ }^{[6-e]} \mathrm{Ru}(\mathrm{II}),{ }^{[6-i]}\right]$ $\operatorname{Ir}(\mathrm{III}),{ }^{[6 \mathrm{j}]}$ and electrochemistry, ${ }^{\left[{ }^{[\mathrm{k}]}\right.}$ amongst others. ${ }^{[4]}$ In particular, samarium(II) iodide $\left(\mathrm{Sml}_{2}\right)$ is the reagent most frequently used to generate ketyl radicals and the reactive intermediates formed in this way have found widespread application in myriad cyclization and cyclization cascade strategies ${ }^{[5]}$ thus establishing both reagent and reaction as standard tools for synthesis. ${ }^{[7]}$ Unfortunately, the formation of ketyl-type radicals is typically limited to aldehyde or ketone substrates, regardless of the reagent used for radical generation. Recently, we and others have begun to extend the rich chemistry of ketyl-type radicals to the reductive cyclizations of carboxylic acid derivatives, ${ }^{[8 a]}$ including cyclic esters ${ }^{[8 \mathrm{~b}-\mathrm{d}]}$ and cyclic amide derivatives, ${ }^{[8-\mathrm{e}-\mathrm{j}]}$ possessing more electron-rich carbonyls. However, engaging carbonyl-containing substrates in which the carbonyl is flanked by two heteroatom substituents in ketyl-type radical chemistry, until now, has not proved possible, despite the promise of new reaction space for exploration.

From the birth of organic synthesis in $1828,{ }^{[9]}$ ureas, possessing carbonyls flanked by two nitrogen atoms, have remained an important compound class with members widely used as

[a] Dr. H.-M. Huang, Dr. J. J. W. McDouall, Prof. Dr. D. J. Procter School of Chemistry, Oxford Road, University of Manchester, Manchester, M13 9PL, UK

E-mail: david.j.procter@manchester.ac.uk

Supporting information for this article is given via a link at the end of the document.((Please delete this text if not appropriate)) catalysts, ligands, drugs, and materials, and exhibiting roles in nature. ${ }^{[10]}$ From a synthetic perspective, the electron rich character of the urea carbonyl typically exempts them from the signature reactions of the carbonyl group. Furthermore, their resistance to SET reduction ${ }^{[10 d]}$ ensures that there are no examples of ketyl-type radical generation from urea carbonyls and therefore no examples of carbon-carbon bond formation using the hypothetical radical anions (Scheme 1A). ${ }^{[11]}$ Herein, we report the first examples of reductive cyclizations and cyclization cascades involving ketyl-type radicals derived from the carbonyl groups of urea derivatives by reductive SET (Scheme 1B). $\mathrm{Sml}_{2}$ activated by a protic additive (e.g. $\mathrm{H}_{2} \mathrm{O}$ ) and $\mathrm{LiBr}$ is used to mediate SET and the choice of protic additive can be used to switch cleanly between two reaction pathways that deliver bicyclic scaffolds resembling those found in numerous natural products. ${ }^{[12]}$ Furthermore, radical cyclization cascades are described in which both radical anion intermediates formed during the sequential SET reduction of ureas are harnessed for multiple carbon-carbon bond formation.

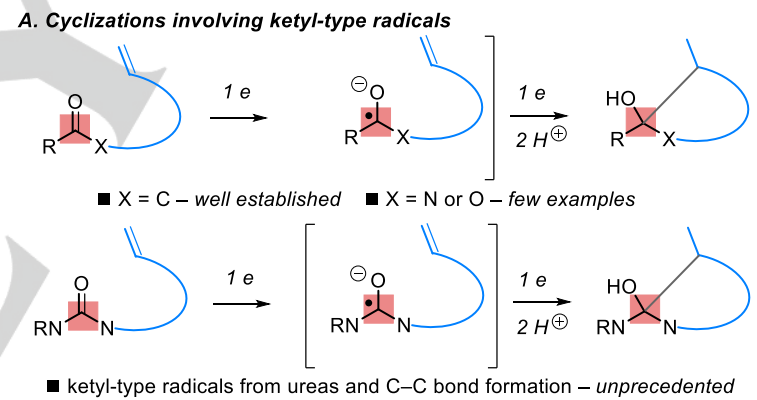

B. Cyclizations and cyclization cascades of ketyl-type radicals from ureas

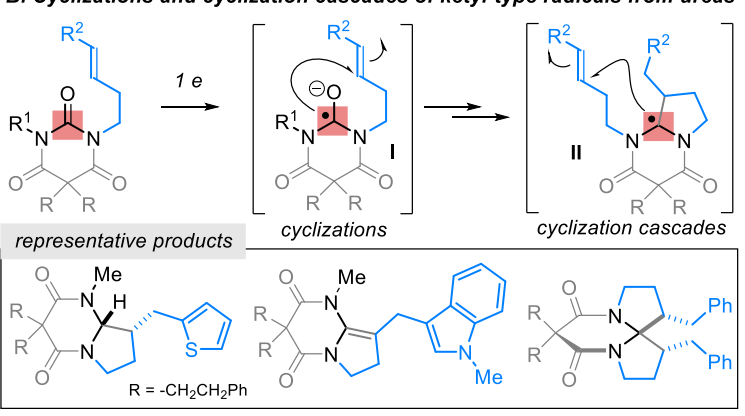

Scheme 1. (A) Radical cyclizations involving ketyl-type radicals. (B) New radical cyclizations and cyclization cascades involving ketyl-type radicals from ureas: this work.

During our studies on reductive SET to important heterocyclic substrates, we prepared barbiturates $\mathbf{1 a , b}$ in three steps from the corresponding substituted malonate esters. Treatment of 1a $\left(\mathrm{R}=\mathrm{CH}_{3}\right)$ with $\mathrm{Sml}_{2}$ in the presence of $\mathrm{H}_{2} \mathrm{O}$ and $\mathrm{LiBr}$ gave bicyclic enamine $\mathbf{2 a}$. $^{8 f, g}$ The process involves cyclization of a radical anion from the amide-type carbonyl followed by dehydration (Scheme 2). Surprisingly, when the starting material 1b $(\mathrm{R}=\mathrm{Et})$ was treated under identical conditions, novel bicyclic 
aminal 3b was obtained in $64 \%$ yield and with complete diastereocontrol. Surprisingly, $\mathbf{3 b}$ results from cyclization involving a radical anion derived from the urea carbonyl (Scheme 2).

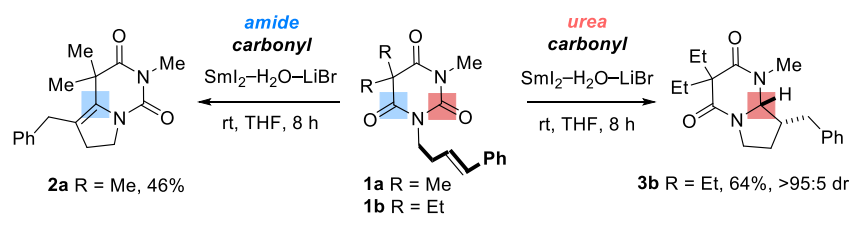

Scheme 2. Switching between the radical cyclization of an amide-type carbonyl and a urea-type carbonyl.

Optimization studies ${ }^{[13]}$ using substrate $1 \mathrm{c}$ revealed that $\mathrm{LiBr}$ and $\mathrm{H}_{2} \mathrm{O}$ were essential for the cyclization to form bicyclic aminals and $3 \mathrm{c}$ was obtained in $75 \%$ yield and as a single diastereoisomer (Conditions A): no urea cyclization was seen in the absence of the additives. The use of $\mathrm{Lil}$ and $\mathrm{LiCl}$ in the place of $\mathrm{LiBr}$ resulted in lower conversions. Interestingly, the use of $t \mathrm{BuOH}$ as a proton source in place of $\mathrm{H}_{2} \mathrm{O}$ gave $3 \mathrm{c}^{\prime}$ in $60 \%$ yield, the enediamine product of urea radical cyclization followed by dehydration (Conditions B). Thus, the urea radical cyclization could be switched between products of differing oxidation state by a simple change in protic cosolvent (Scheme 3).

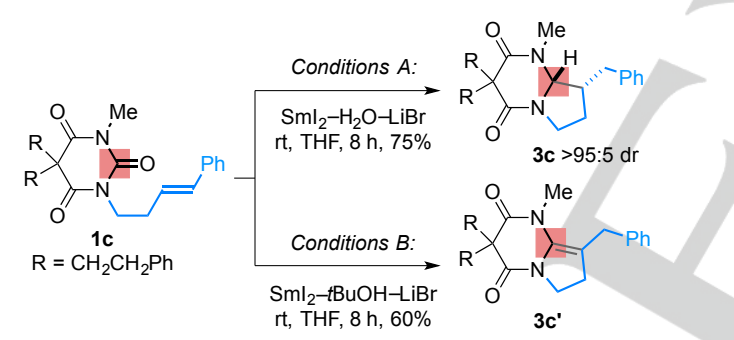

Scheme 3. Optimized reaction conditions allow switching between cyclization outcomes upon a change of protic cosolvent.

It is known that the use of $\mathrm{H}_{2} \mathrm{O}$ as a protic additive with $\mathrm{Sml}_{2}$ gives rise to a more reducing reagent system. ${ }^{[14]}$ Thus, Conditions A deliver more-reduced products than Conditions B. The role of $\mathrm{LiBr}$ is also crucial. Flowers has demonstrated that adding $\mathrm{LiBr}$ to $\mathrm{Sml}_{2}(-0.9 \mathrm{~V}$ vs SCE) generates more reducing $\mathrm{SmBr}_{2}\left(-1.55 \mathrm{~V}\right.$ vs SCE) in situ. ${ }^{[15]}$ In the presence of $\mathrm{H}_{2} \mathrm{O}$ (Conditions $\mathrm{A}$ ), $\mathrm{SmBr}_{2}$ is even more reducing and has recently shown unique properties in radical cyclization and cyclization cascades. ${ }^{[16,8 f, g]}$

With optimized conditions established, the synthesis of a range of bicyclic aminals 3 was achieved using $\mathrm{Sml}_{2}-\mathrm{H}_{2} \mathrm{O}-\mathrm{LiBr}$ (Scheme 4). In all cases, urea radical cyclizations proceeded efficiently and with complete diastereocontrol (>95:5 dr). Furthermore, changing to the $\mathrm{Sml}_{2}-\mathrm{tBuOH}-\mathrm{LiBr}$ reagent system switched the chemoselectivity of the radical process to give

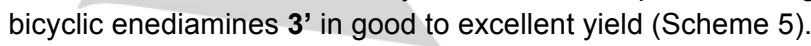

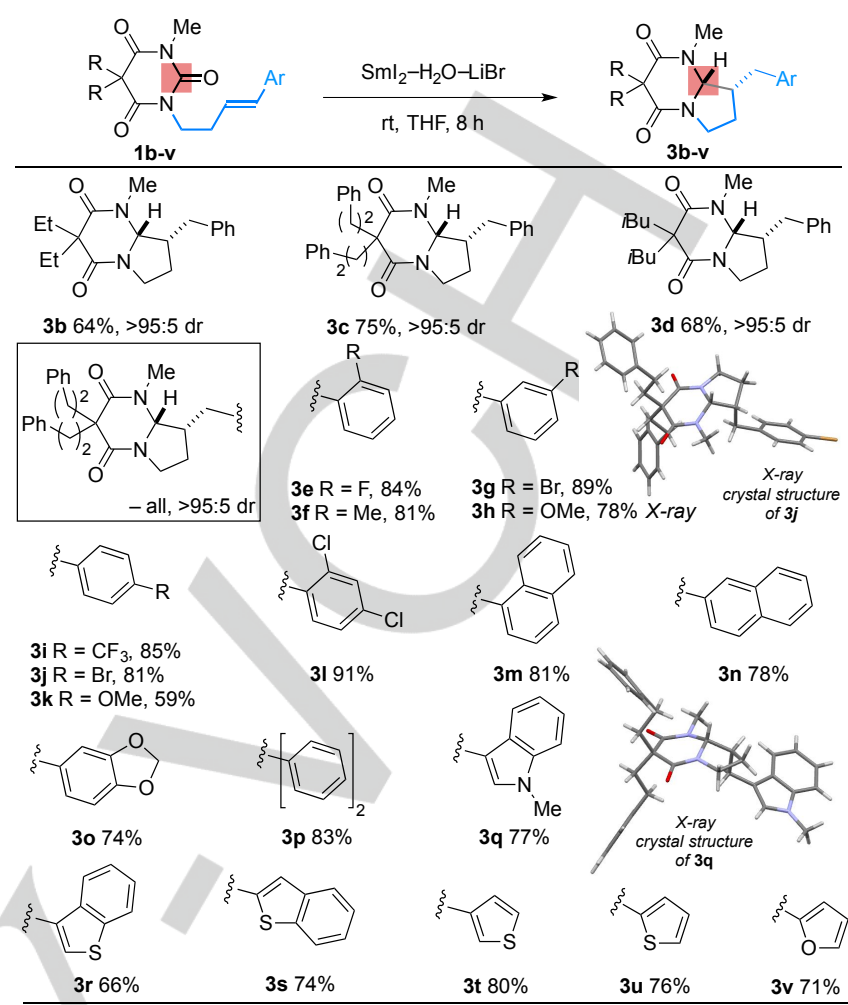

Scheme 4. Scope of urea radical cyclizations to form bicyclic aminal products 3. Reaction conditions: To a solution of $1(0.1 \mathrm{mmol})$, in THF $(2 \mathrm{~mL})$ under $\mathrm{N}_{2}$, was added $\mathrm{H}_{2} \mathrm{O}$ (100 equiv), followed by a mixture of $\mathrm{Sml}_{2}$ (5 equiv) and $\mathrm{LiB}$ (20 equiv with respect to $\mathrm{Sml}_{2}$ ), the reaction was quenched after $8 \mathrm{~h}$. Dr was determined from ${ }^{1} \mathrm{H}$ NMR of crude product mixtures.

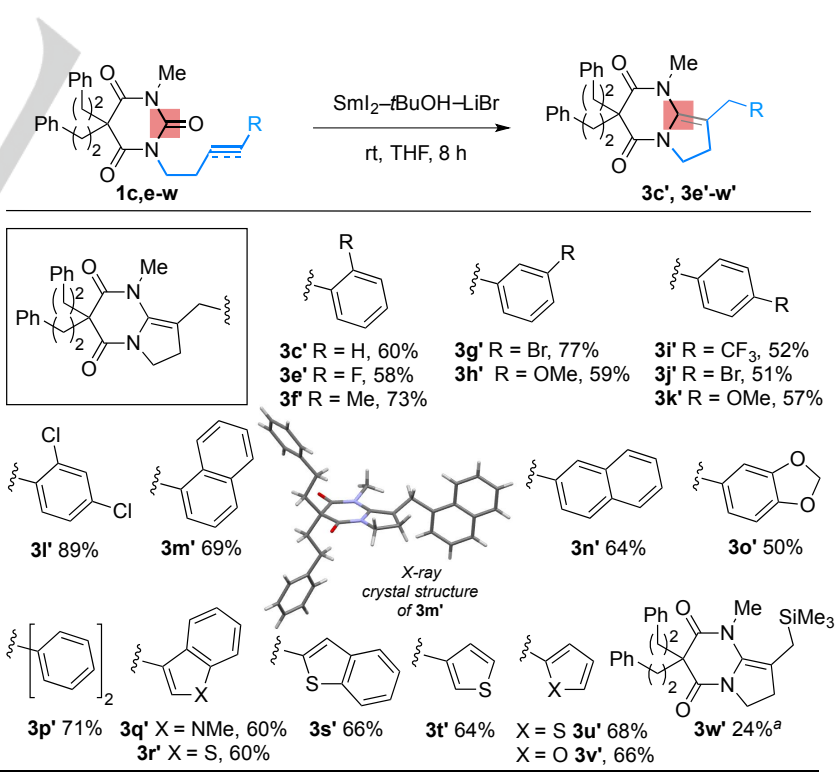

Scheme 5. Scope of urea radical cyclizations to form bicyclic enediamines 3'. Reaction conditions: To a solution of $1(0.1 \mathrm{mmol})$, in THF $(2 \mathrm{~mL})$ under $\mathrm{N}_{2}$, was added $t \mathrm{BuOH}$ (10 equiv), followed by a mixture of $\mathrm{Sml}_{2}$ (3 equiv) and $\mathrm{LiBr}$ (20 equiv with respect to $\mathrm{Sml}_{2}$ ), the reaction was quenched after $8 \mathrm{~h}$. The corresponding aminals 3c, 3e-v were obtained in less than $5 \%$ yield. ${ }^{a}$ Prepared by 5-exo-dig cyclization of alkynyl silane $1 \mathrm{w}(\mathrm{R}=\mathrm{TMS})$ using $\mathrm{Sml}_{2}-$ $\mathrm{H}_{2} \mathrm{O}-\mathrm{LiBr}$. 
The reductive processes are compatible with various alkyl substituents (3b-d) and a wide range of functional groups including fluoro (3e and $\mathbf{3} \mathbf{e}^{\mathbf{\prime}}$ ), bromo $\left(\mathbf{3} \mathbf{g}, \mathbf{3} \mathbf{j}\right.$ and $\mathbf{3} \mathbf{g}^{\prime}, \mathbf{3} \mathbf{j}$ '), chloro ( $3 \mathbf{l}$ and $\left.\mathbf{3} \mathbf{l}^{\prime}\right)$, methoxy (3h, $\mathbf{3} \mathbf{k}$ and $\left.\mathbf{3} \mathbf{h}^{\prime}, \mathbf{3} \mathbf{k}^{\prime}\right)$, trifluoromethyl ( $\mathbf{i} \mathbf{i}$ and $3 \mathbf{i}^{\prime}$ ) and acetal (3o and 3o'). The reductive radical cyclizations were also compatible with important heteroaromatic rings including indole ( $\mathbf{3 q}$ and $\left.\mathbf{3} \mathbf{q}^{\mathbf{\prime}}\right)$, benzothienyl (3r, $\mathbf{3} \mathbf{s}$ and $\mathbf{3} \mathbf{r}^{\text {', }}$ $\mathbf{3} \mathbf{s}^{\prime}$ ), thienyl (3t, $\mathbf{3} \mathbf{u}$ and $\left.\mathbf{3} \mathbf{t}^{\prime}, \mathbf{3} \mathbf{u}^{\prime}\right)$ and furanyl (3v and $\left.\mathbf{3} \mathbf{v}^{\prime}\right)$. X-ray crystallographic analysis of $\mathbf{3 h}, \mathbf{3 j}, \mathbf{3 q}$ and $\mathbf{3} \mathrm{m}^{\prime}$ confirmed the structures and, where relevant, the relative stereochemistry of the radical cyclization products. ${ }^{[17]}$ Interestingly, bicyclic enediamine $3 w^{\prime}$ was obtained by 5 -exo-dig cyclization of an alkynylsilane $1 \mathrm{w}$ in moderate isolated yield. An attempted 6-exotrig cyclization was unsuccessful. ${ }^{[13]}$

We next investigated radical cyclization cascades in which both radical intermediates (I and II, Scheme 1) formed during reduction of the urea carbonyl were trapped. Substrates 4 bearing alkene radical traps on both nitrogen atoms were prepared in three steps from commercially available diethyl 2,2diphenethylmalonate. Upon exposure to $\mathrm{Sml}_{2}-\mathrm{H}_{2} \mathrm{O}-\mathrm{LiBr}$, spirocyclic aminal cyclization cascade products $\mathbf{5}$ were obtained in moderate isolated yield as a mixture of diastereoisomers. The structure of the major diasteroisomer of $\mathbf{5 a}$ was confirmed by $X$ ray crystallographic analysis. ${ }^{[17]}$ The urea radical cyclization cascade was found to be compatible with chloro (5b), naphthyl (5d), and benzothienyl (5e) motifs (Scheme 6).

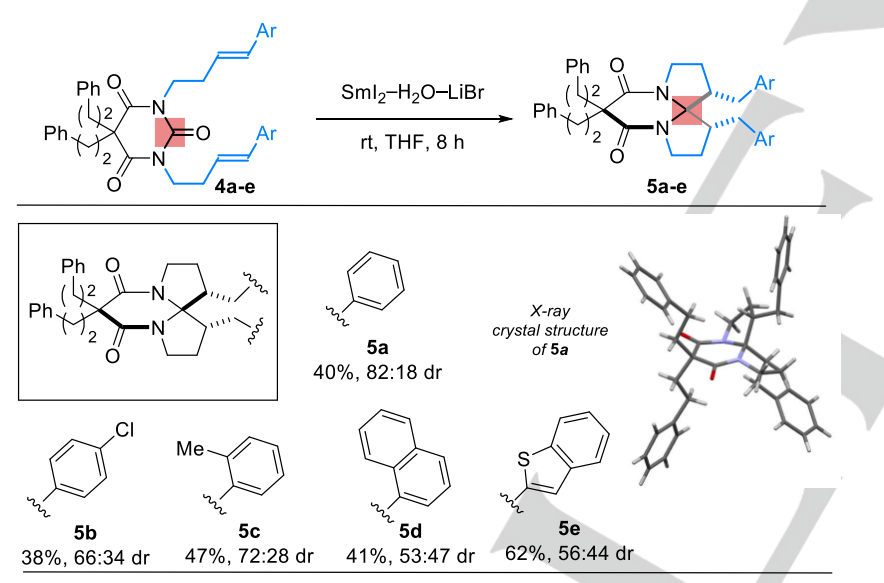

Scheme 6. Scope of urea radical cyclization cascades. Reaction conditions: to a solution of $4(0.1 \mathrm{mmol})$, in THF $(2 \mathrm{~mL})$ under $\mathrm{N}_{2}$, was added $\mathrm{H}_{2} \mathrm{O}(100$ equiv), followed by a mixture of $\mathrm{Sml}_{2}$ (5 equiv) and $\mathrm{LiBr}$ (20 equiv with respect to $\mathrm{Sml}_{2}$ ), the reaction was quenched after $8 \mathrm{~h}$. Dr was determined from ${ }^{1} \mathrm{H}$ NMR of crude product mixtures.

Larger scale transformations of 1c $(2 \mathrm{mmol}, 0.96 \mathrm{~g})$ gave bicyclic products 3c $(70 \%, 0.66 \mathrm{~g})$ and $3 \mathrm{c}$ ' $(51 \%, 0.47 \mathrm{~g})$, respectively (Scheme $7 \mathrm{~A}$ ). Experimental and computational studies have been used to explore the mechanism of the urea radical cyclizations (Scheme 7B,C). A labeling study confirms that anions are generated and protonated during the formation of aminal 3c from 1c using $\mathrm{Sml}_{2}-\mathrm{H}_{2} \mathrm{O}-\mathrm{LiBr}$ : Use of $\mathrm{D}_{2} \mathrm{O}$ with $\mathrm{Sml}_{2}$ and $\mathrm{LiBr}$ converted $1 \mathrm{c}$ to deuterated bicyclic aminal $3 \mathrm{c}-\mathrm{D}_{2}$ in $69 \%$ yield. The labeling pattern in $3 c-D_{2}$ suggests that the final stage of aminal formation proceeds by reduction of an iminium ion intermediate rather than by formation and reduction of enediamine 3c'.
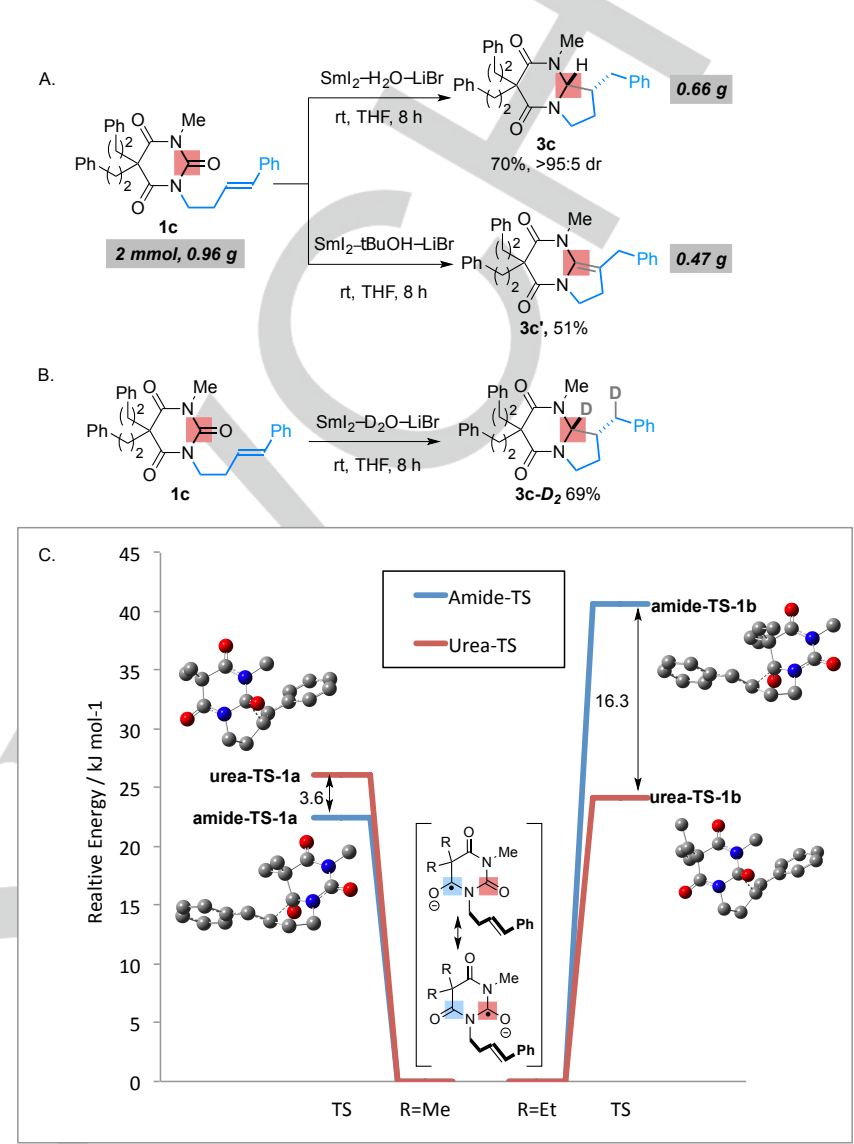

Scheme 7. Preliminary mechanistic studies.

The nature of the radical anion formed upon SET to the barbituric acid system has been explored computationally. Calculations suggest that the spin density is delocalized ${ }^{[18]}$ although the highest spin density can be found on the amidetype carbonyl $\left(0.19\right.$ total spin density on $\mathrm{C}=\mathrm{O}_{\text {amide }}$ and 0.14 on the urea carbonyl in the radical anion derived from $1 \mathrm{a} ; 0.18$ total spin density on $\mathrm{C}=\mathrm{O}_{\text {amide }}$ and 0.15 on the urea carbonyl in the radical anion derived from $\mathbf{1 b}$ ). Thus, the switch from amide radical cyclization (observed for $\mathbf{1 a}$ ) to urea radical cyclization (observed for $\mathbf{1 b}$ ) is likely the result of selective trapping of a delocalized radical at two different sites. Calculated relative transition state energies support the experimental observations (Scheme 7C): the transition state energy for the amide cyclization of the radical anion derived from $1 a(R=M e)$ (amide TS-1a) is calculated to be $3.6 \mathrm{kJmol}^{-1}$ lower in energy than that of the analogous urea cyclization. Conversely, the transition state energy for the urea cyclization of the radical anion derived from 1b $(R=E t)$ (urea TS-1b) is calculated to be $16.3 \mathrm{kJmol}^{-1}$ lower in energy than that of the analogous amide cyclization. The switch likely arises from an increased barrier to amide cyclization in the radical anion derived from $\mathbf{1 b}$ relative to the 
urea radical cyclization due to the greater steric demands of the proximal ethyl groups. ${ }^{[19]}$ As expected, anti-transition states were found to be the lowest in energy in all cases. ${ }^{[5]}$

A proposed mechanism for the urea radical cyclization is shown in Scheme 8. SET to substrates $\mathbf{1}$ and $\mathbf{4}$ gives delocalized radical anion 6 . When $\mathrm{R}^{\prime}$ is larger than Me, carbon-carbon bond formation takes place at what was the carbon of the urea carbonyl and 5-exo-trig cyclization gives the corresponding bicyclic Sm(III) alkoxide intermediates 7 (Scheme 8).

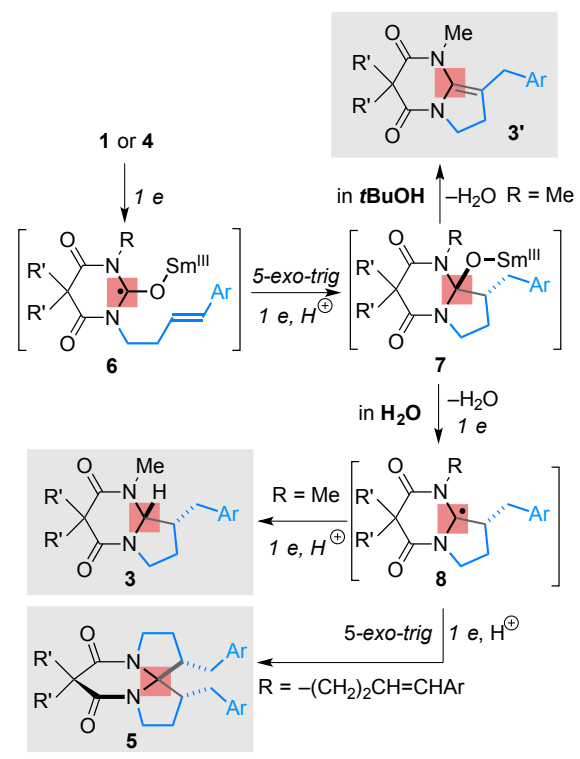

Scheme 8. Proposed mechanism for the urea radical cyclizations.

When $\mathrm{tBuOH}$ is used as the proton source, bicyclic enediamines 3' are obtained upon elimination. In contrast, when $\mathrm{H}_{2} \mathrm{O}$ is used, the more reducing reagent system forms aminal radicals 8 and further reduction and protonation delivers bicyclic aminals 3 . When the $\mathrm{R}$ group in $\mathbf{8}$ contains a radical trap, the aminal radicals undergo cyclization to give cascade products $\mathbf{5}$, after further reduction and protonation.

In summary, ketyl-type radical anions derived from the urea carbonyl by reductive SET undergo, intramolecular carboncarbon bond formation. Depending upon the proton source used in the radical reactions, a chemoselective switch between reaction pathways delivers two important heterobicyclic scaffolds. Computational studies have been employed to explore the natural of the radical anion intermediates and their selective radical cyclization. Furthermore, radical cyclization cascades involving radicals derived from ureas by SET deliver unusual spirocyclic aminal architectures.

\section{Acknowledgements}

We thank the EPSRC (EPSRC Established Career Fellowship to D.J.P.), the Leverhulme Trust (Research Fellowship to D.J.P.), and the University of Manchester (President's Scholarship to H.H.) for funding.
Keywords: urea $\cdot$ radical $\cdot$ cyclization $\cdot$ samarium $\cdot$ nitrogen heterocycles

[1] a) L. Yin, J. Liebscher, Chem. Rev. 2007, 107, 133-173; b) N Rodríguez, L. J. Goossen, Chem. Soc. Rev. 2011, 40, 5030-5048; c) M. Fagnoni, D. Dondi, D. Ravelli, A. Albini, Chem. Rev. 2007, 107, 27252756; d) J. Choi, G. C. Fu, Science 2017, 356, eaaf7230.

[2] a) J. Iqbal, B. Bhatia, N. K. Nayyar, Chem. Rev. 1994, 94, 519-564; b) G. Bar, A. F. Parsons, Chem. Soc. Rev. 2003, 32, 251; c) M. Yan, J. C. Lo, J. T. Edwards, P. S. Baran, J. Am. Chem. Soc. 2016, 138, 1269212714; d) A. Studer, D. P. Curran, Nat. Chem. 2014, 6, 765-773; e) A. Studer, D. P. Curran, Angew. Chem., Int. Ed. 2016, 55, 58-102; Angew. Chem. 2016, 128, 58-106.

[3] a) M. P. Plesniak, H.-M. Huang, D. J. Procter, Nat. Rev. Chem. 2017, 1, 0077; b) E. A. Anderson, Org. Biomol. Chem. 2011, 9, 3997; c) K. C. Nicolaou, J. S. Chen, Chem. Soc. Rev. 2009, 38, 2993; d) K. C. Nicolaou, D. J. Edmonds, P. G. Bulger, Angew. Chem., Int. Ed. 2006, 45, 7134-7186; e) K. K. Wang, Chem. Rev. 1996, 96, 207-222; f) L. F. Tietze, Chem. Rev. 1996, 96, 115-136.

[4] a) K. N. Lee, M.-Y. Ngai, Chem. Commun. 2017, 53, 13093-13112; b) J. Cossy, D. Belotti, Tetrahedron 2006, 62, 6459-6470; c) A. Gansäuer, H. Bluhm, Chem. Rev. 2000, 100, 2771-2788.

[5] a) M. Szostak, N. J. Fazakerley, D. Parmar, D. J. Procter, Chem. Rev. 2014, 114, 5959-6039; b) C. Beemelmanns, H.-U. Reissig, Chem. Soc. Rev. 2011, 40, 2199-2210; c) C. Beemelmanns, H.-U. Reissig, Pure Appl. Chem. 2011, 83, 507-518; d) K. C. Nicolaou, S. P. Ellery, J. S. Chen, Angew. Chem., Int. Ed. 2009, 48, 7140-7165; e) R. Flowers, II, Synlett 2008, 2008, 1427-1439; f) D. J. Edmonds, D. Johnston, D. J. Procter, Chem. Rev. 2004, 104, 3371-3403; g) G. A. Molander, C. R. Harris, Chem. Rev. 1996, 96, 307-338.

[6] a) Y.-Q. Zhang, E. Vogelsang, Z.-W. Qu, S. Grimme, A. Gansäuer, Angew. Chem., Int. Ed. 2017, 56, 12654-12657; b) W. Hao, X. Wu, J. Z. Sun, J. C. Siu, S. N. MacMillan, S. Lin, J. Am. Chem. Soc. 2017, 139, 12141-12144; c) J. Streuff, Chem. Rec. 2014, 14, 1100-1113; d) J. Streuff, M. Feurer, P. Bichovski, G. Frey, U. Gellrich, Angew. Chem., Int. Ed. 2012, 51, 8661-8664; e) A. Fürstner, B. Bogdanović, Angew. Chem., Int. Ed. 1996, 35, 2442-2469; f) E. C. Gentry, R. R. Knowles, Acc. Chem. Res. 2016, 49, 1546-1556; g) A. G. Amador, E. M. Sherbrook, T. P. Yoon, J. Am. Chem. Soc. 2016, 138, 4722-4725; h) H. Yayla, R. Knowles, Synlett 2014, 25, 2819-2826; i) J. Du, K. L. Skubi, D. M. Schultz, T. P. Yoon, Science 2014, 344, 392-396; j) L. J. Rono, H. G. Yayla, D. Y. Wang, M. F. Armstrong, R. R. Knowles, J. Am. Chem. Soc. 2013, 135, 17735-17738; k) T. Shono, N. Kise, T. Fujimoto, N. Tominaga, H. Morita, J. Org. Chem. 1992, 57, 7175-7187.

[7] Selected recent examples: a) N. J. Fazakerley, M. D. Helm, D. J. Procter, Chem. -Eur. J. 2013, 19, 6718-6723; b) M. D. Helm, M. Daâ Silva, D. Sucunza, T. J. â. K. Findley, D. J. Procter, Angew. Chem., Int. Ed. 2009, 48, 9315-9317; c) S. E. Reisman, J. M. Ready, M. M. Weiss, A. Hasuoka, M. Hirata, K. Tamaki, T. V Ovaska, C. J. Smith, J. L. Wood, J. Am. Chem. Soc. 2008, 130, 2087-2100; d) J. Y. Cha, J. T. S. Yeoman, S. E. Reisman, J. Am. Chem. Soc. 2011, 133, 14964-14967; e) J. T. S. Yeoman, V. W. Mak, S. E. Reisman, J. Am. Chem. Soc. 2013, 135, 11764-11767; f) K. C. Nicolaou, A. Li, D. J. Edmonds, G. S. Tria, S. P. Ellery, J. Am. Chem. Soc. 2009, 131, 16905-16918; g) T. Xu, C. C. Li, Z. Yang, Org. Lett. 2011, 13, 2630-2633; h) G. K. Murphy, T. Shirahata, N. Hama, A. Bedermann, P. Dong, T. C. McMahon, B. M. Twenter, D. A. Spiegel, I. M. McDonald, N. Taniguchi, et al., J. Org. Chem. 2013, 78, 477-489; i) C. Beemelmanns, H.-U. Reissig, Angew. Chem., Int. Ed. 2010, 49, 8021-8025; j) Z. Li, M. Nakashige, W. J. Chain, J. Am. Chem. Soc. 2011, 133, 6553-6556.

[8] a) X. Just-Baringo, D. J. Procter, Acc. Chem. Res. 2015, 48, $1263-$ 1275. Selected examples: b) K. D. Collins, J. M. Oliveira, G. Guazzelli, B. Sautier, S. De Grazia, H. Matsubara, M. Helliwell, D. J. Procter, Chem. -Eur. J. 2010, 16, 10240-10249; c) B. Sautier, S. E. Lyons, M. R. Webb, D. J. Procter, Org. Lett. 2012, 14, 146-149; d) D. Parmar, H. 
Matsubara, K. Price, M. Spain, D. J. Procter, J. Am. Chem. Soc. 2012, 134, 12751-12757; e) M. Szostak, B. Sautier, M. Spain, M. Behlendorf, D. J. Procter, Angew. Chem., Int. Ed. 2013, 52, 12559-12563; f) H.-M. Huang, D. J. Procter, J. Am. Chem. Soc. 2016, 138, 7770-7775; g) H.M. Huang, D. J. Procter, J. Am. Chem. Soc. 2017, 139, 1661-1667; h) S. Shi, M. Szostak, Org. Lett. 2015, 17, 5144-5147; i) S. Shi, R. Lalancette, R. Szostak, M. Szostak, Chem. -Eur. J. 2016, 22, 11949 11953; j) S. Shi, R. Lalancette, M. Szostak, Synthesis 2016, 48, 18251854.

[9] F. Wöhler, Ann. Phys. Chem. 1828, 88, 253-256.

[10] a) R. Chingle, C. Proulx, W. D. Lubell, Acc. Chem. Res. 2017, 50, 1541-1556; b) P. Dydio, D. Lichosyt, J. Jurczak, Chem. Soc. Rev. 2011 40, 2971; c) H.-Q. Li, P.-C. Lv, T. Yan, H.-L. Zhu, Anticancer. Agents Med. Chem. 2009, 9, 471-480; d) N. Volz, J. Clayden, Angew. Chem., Int. Ed. 2011, 50, 12148-12155.

[11] For the reduction of cyclic ureas to the corresponding aminals using $\mathrm{LiAH}_{4}$ and $\mathrm{LiBH}_{4}$, see: a) H. A Bates, N. Condulis, N. L. Stein, J. Org. Chem. 1986, 51, 2228-2229; b) D. J. Conn, J. J. Kaminski, D. M. Solomon, A. T. McPhail, J. Org. Chem. 1988, 53, 3265-3271.

[12] For recent reports of natural products possessing related structures, see: a) S. D. Vaidya, N. P. Argade, Org. Lett. 2015, 17, 6218-6221; b) I. Bosque, J. C. Gonzalez-Gomez, M. I. Loza, J. Brea, J. Org. Chem. 2014, 79, 3982-3991; c) C. Zhang, C. K. De, R. Mal, D. Seidel, J. Am. Chem. Soc. 2008, 130, 416-417; d) J.-F. Liu, P. Ye, K. Sprague, K.
Sargent, D. Yohannes, C. M. Baldino, C. J. Wilson, S.-C. Ng, Org. Lett 2005, 7, 3363-3366.

[13] See supporting information.

[14] a) P. R. Chopade, E. Prasad, R. A. Flowers, II, J. Am. Chem. Soc. 2004 126, 44-45; b) E. Prasad, R. A. Flowers, II, J. Am. Chem. Soc. 2005 127, 18093-18099.

[15] a) J. R. Fuchs, M. L. Mitchell, M. Shabangi, R. A. Flowers, II, Tetrahedron Lett. 1997, 38, 8157-8158; b) R. S. Miller, J. M. Sealy, M. Shabangi, M. L. Kuhlman, J. R. Fuchs, R. A. Flowers, II, J. Am. Chem. Soc. 2000, 122, 7718-7722; c) B. W. Knettle, R. A. Flowers, II, Org. Lett. 2001, 3, 2321-2324.

[16] a) C. N. Rao, D. Lentz, H.-U. Reissig, Angew. Chem., Int. Ed. 2015, 54, 2750-2753; b) C. N. Rao, C. Bentz, H.-U. Reissig, Chem. -Eur. J. 2015, $21,15951-15954$.

[17] See the Supporting Information for X-ray structures. CCDC 1586111 (3h), CCDC 1586112 (3j), CCDC 1586113 (3q), CCDC 1586114 (3m'),CCDC 1586115 (5a) contain the supplementary crystallographic data for this paper. These data can be obtained free of charge from The Cambridge Crystallographic Data Centre.

[18] For an early EPR and computational study, see: H. C. Box, E. E. Budzinski, J. Chem. Phys. 1973, 59, 1588-1591.

[19] Although our calculations do not involve samarium, two Sm(III) ions could be incorporated in the resonance forms set out in Scheme 7; one associated with the ketyl radical anion and one with the other carbonyl. 


\section{Entry for the Table of Contents}

\section{COMMUNICATION}

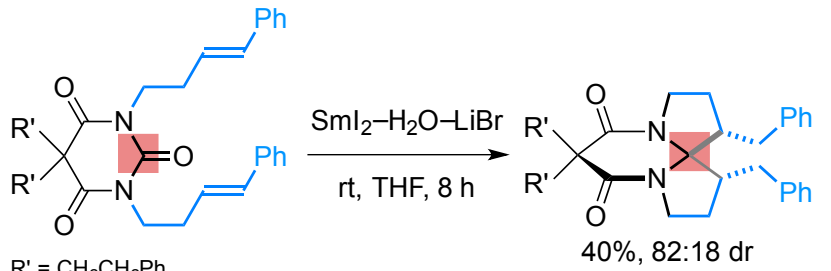

$\mathrm{R}^{\prime}=\mathrm{CH}_{2} \mathrm{CH}_{2} \mathrm{Ph}$

ketyl-type radical anions from ureas

- radical cyclizations $\&$ cascades -46 examples

- cosolvent dependent switching between products $n$ computational studies

Radical anions generated from urea carbonyls by reductive electron transfer are exploited in carbon-carbon bond formation. New radical cyclizations of urea radical anions deliver complex nitrogen heterocycles and, depending upon the proton source used in the reactions, a chemoselective switch between reaction pathways can deliver two heterobicyclic scaffolds. A computational study has been used to investigate the selectivity of the urea radical processes. Furthermore, radical cyclization cascades involving urea radical anions deliver unusual spirocyclic aminal architectures.
Huan-Ming Huang, Joseph J. W. McDouall, and David J. Procter*

\author{
Page No. - Page No.
}

Radical Anions from Urea-type Carbonyls: Radical Cyclizations and Cyclization Cascades 